\title{
Felípica, capital de la monarquía (propuestas de Pérez de Herrera para Madrid)
}

\author{
Dolores González de la Fuente *
}

\section{RESUMEN ABSTRACT}

En una época de crisis donde se tambalea la hegemonia de la monarquía hispánica, Cristóbal Pérez de Herrera propone un ambicioso proyecto encaminado a sanear la sociedad cuya imagen visible será su

capital, un nuevo Madrid renovado hasta en su denominación, Felípica, la corte de los Austrias españoles, en la que arquitectura y urbanismo puestos al servicio del poder político crearán el marco ideal donde se desarrolle la vida cortesana.
In a period of crisis in which the hegemony of the monarchy is in danger. Cristóbal Pérez de Herrera suggests an ambitions project designed to insure a society whose visible image will be its capital: a new and reorganized Madrid, renewed even in its name "Felipica", it will be the court of the Spanish Austrias, where architecture and urban development are at the disposal of the political authorities to create the ideal framework where the life of the Court will develop.

Cristóbal Pérez de Herrera, Protomédico de las Galeras Reales, Médico de su Majestad y con el tiempo Procurador General de los Pobres de España ${ }^{1}$ es un importante personaje de su tiempo, la transición del siglo XVI al

Licenciada en Historia del Arte.

C. Pérez de Herrera (Salamanca 1556-Madrid 1620). Para profundizar en la biografia del doctor. Perez de HeRRera, C. Relación de los mvchos, y particulares seruicios. que por espacio de quarenta y un años del Doctor..., protomedico de las galeras de España. Medico del Rey N.S. y del Reyno Protector y Procurador general de los pobres y albergues del, ha hecho a la Magestad del Rey don Felipe II que està en el cielo. y a la de don Felipe III N.S. que Dios guarde muchos y fe. licissimos años, BN, R-28.762. MORE.JON. A. F. Historia Bibliográfica de la Medicina Española, t. IV. 
XVII, y por ello resulta cita obligada como ejemplo de opinión cualificada, para comprender las inquietudes de los hombres de su época y para evaluar la posibilidad que tenian los intelectuales de intervenir materialmente en la sociedad del momento. Los intereses de Pérez de Herrera se centrarán, además de en el tema de la Medicina, en la restauración general de la república y, teniendo ésta como marco general, aborda desde el tratamiento que se debe dar a la lacra social que supone la mendicidad, hasta asuntos de índole urbanística referidos concretamente a la ciudad de Madrid, por ser la capital del estado y por tanto elemento fundamental propagandístico, ya que la capital determina la imagen del estado en el país y en el resto del mundo. La relevancia de sus aportaciones en el tema del urbanismo justifican un estudio profundo de su visión de ciudad, sin olvidar el carácter unitario de toda su obra ${ }^{2}$.

Todas sus propuestas se encaminan a conseguir una reforma general de la sociedad, un cambio de valores en donde se prime la laboriosidad y el servicio a la república tratando de lograr así una sociedad perfectamente reglamentada y ordenada. Este objetivo no es único ni original entre sus contemporáneos sino que se inscribe dentro de una corriente intelectual reformadora ${ }^{3}$, formada por pensadores denominados comúnmente arbitristas, que pretenden lograr la renovación de la sociedad a fin de mantener la hegemonía de la monarquía hispánica frente al resto de las potencias europeas. La grave crisis en la que se ve inmersa la nación a finales del XVI y durante todo el XVII, hará que estos estudiosos, podríamos calificarlos como pre-economistas y pre-sociólogos ${ }^{4}$, se sientan inclinados a publicar y enviar una ingente cantidad de memoriales a las diversas administraciones del reino, en los que apuntan soluciones a los problemas con los que se enfrenta el país: la despoblación, la continuada subida de precios de productos básicos, la falta de moneda y su terrible devaluación... Estas sugerencias o "arbitrios» darán el nombre de "arbitristas» a quienes escriben Memoriales. Pronto el calificativo de "arbitrista" tendrá un matiz peyorativo al entender que muchos de aquellos escritos no son

Madrid 1846, p.117. GRANJEL, L. S. Médicos españoles, Salamanca 1967. Maranón, G. Obras completas, vol. IV, Madrid 1968. Sierra Corella, A. "Los forjadores de la grandeza de Madrid. El doctor Cristóbal Pérez de Herrera", RBAM, n."1-2, Madrid 1950, págs. 231-250.

Un estudio de conjunto más completo sobre la verdadera dimensión intelectual de Pérez de Herrera se puede consultar en nuestro trabajo inédito Proyecto-Madrid: Cristóbal Pérez de Herrera, propuestas urbanisticas para una nueva capital, UNED, Madrid 2001.

Pérez de Herrera, C. Amparo de pobres. Edición, introducción y notas de M. Cavillac. Madrid 1975. págs. 46-47

J.L. Pérez de Ayala en la edicion de Gonzalez de Cellorigo. M. Memorial de la politica necesario y útil restauración de la república de España (1600), Madrid 1991, pág. XV. 
sino vanos ejercicios literarios que no aportan solución alguna ${ }^{5}$. El propio Pérez de Herrera tratará de distanciarse de esta corriente y argumentará que, "por tratar solo de cosas tocantes al bien público no merecen estos mis pensamientos el nombre de "arbitrios" (que el vulgo llama)" " ${ }^{6}$. Ciertamente muchos de aquellos memoriales plantean unos "arbitrios" totalmente inviables, pero en otros se realizan agudos estudios de los males que aquejan a la nación, analizando causas y exponiendo reformas. Todas estas propuestas, y nos referimos especialmente a las que hoy reconocemos como acertadas y que muy bien pudieran haber facilitado paliar la crisis, conllevaban una reforma profunda de las mentalidades y de la estructura social del momento, tal vez en ello radicó su fracaso y no se llegaron a poner en práctica.

Cristóbal Pérez de Herrera entiende la ciudad en sus dos acepciones, como urbs y civitas, y pretende, siguiendo el espíritu regulador de la época, controlar toda la sociedad. Organizar y registrar todos los movimientos y actividades de la población a través de un control férreo de los vecinos, y los que están de paso por medio de alguaciles y de censores que vigilen a la población flotante averiguando a qué ha venido a Madrid y por cuánto tiempo, de tal manera que sea la república una máquina perfecta en la que la vigilancia y el orden son prioridades. Una ciudad limpia, ordenada en cuanto a lugares de venta, situación de los oficios, sin mendigos viciosos ni delincuentes por las calles, salvo pobres verdaderos y acreditados que aparezcan en lugares y horas determinados, una ciudad adornada con monumentos, bellas murallas y jardines. Esta es su intención, crear la ciudad perfecta, emblema de la monarquía y arquetipo de capital moderna. En este marco hay que entender las propuestas que sobre urbanismo hace el doctor, una sociedad perfectamente regulada debe contar con una cabeza visible fija que proyecte al mundo una imagen lo suficientemente prestigiosa como para simbolizar el propio poder del estado que la sustenta. Madrid, como capital de la monarquia debería revestirse de la monumentalidad adecuada para cumplir esta función de imagen del poder español frente al mundo. Es Pérez de Herrera ejemplo de cómo la intelectualidad del momento consideraba la arquitectura como un medio

Sobre la condición y consideración del arbitrista, VILAR, J. Literatura y economía. La figura satirica del arbitrista en el siglo de Oro, Madrid 1973.

6 Curación del cuerpo de la República. o Remedios para el bien de la salud del cuerpo de la República. al Catolico y poderosissimo Rey de las Espanas, y Nueuo mundo, y de otros muchos y grandes reynos y señorios, don Felipe III nuestro señor. En razon de mvchas cosas tocantes al bien. prosperidad. riqueza y tertilidad destos Reynos y restauracion de la gente que se ha echado dellos. Madrid, 1 de mayo de 1610. BN. R-28.762, fol. 30r. 
eficaz de propaganda, como imagen del poder para súbditos y extranjeros que podian apreciar, a través de la contemplación de una ciudad, la organización y el buen gobierno que se ejercía sobre la república. El urbanismo viene a considerarse como una manifestación del buen gobierno.

Pero no será el único que comprende el valor propagandístico de la arquitectura y el urbanismo, desde la propia Corona se impulsa la intervención sobre Madrid a fin de dotarle de una fisonomía acorde con los parámetros estéticos del momento, lo que explica el tesón de influir en el Concejo de la Villa para controlar el crecimiento de la ciudad, y el motivo por el que se crean las Juntas de Policía y Ornato de finales del XVI ${ }^{7}$. Es la línea de actuación que se trata de abrir con los proyectos de reformas iniciados por el Memorial de las obras de Madriz ${ }^{8}$, continuando con las propuestas de las Juntas de Urbanismo y finalizando por los escritos de intelectuales como Pérez de Herrera, o Xerez y Deça ${ }^{9}$, ya a principios del xVII. Proyectos que demuestran cómo la ciudad de Madrid era objeto de reflexión entre los contemporáneos. Se pensaba en ella como un objeto moldeable capaz de proyectar el ideal de capital tal y como se propone en la tratadistica renacentista.

Las Juntas de Policía creadas en Madrid, una en 1580, supervisada por Juan de Herrera, y otra en 1590 bajo la dirección técnica del arquitecto Juan de Valencia y después, al morir éste, de Francisco de Mora, tratarán de controlar el crecimiento que estaba sufriendo la ciudad, este control se queria ejercer tanto en la vida económica de la ciudad, a través de la fijación de lugares de venta de mantenimientos, ubicación de oficios y talleres..., como en el ámbito urbanistico y arquitectónico por medio de la elaboración de una normativa encaminada a mantener limpia la ciudad y construir los edificios siguiendo determinados modelos, de tal manera que se consiguiese la realineación correcta de las vias públicas y su configuración armónica a través de la uniformidad del trazado y del uso de materiales de construcción, especialmente en las calles más importantes de Madrid. Para más información: CAmBronero, C. "Las ordenanzas de Policía Urbana en 1591 "Revista Con-

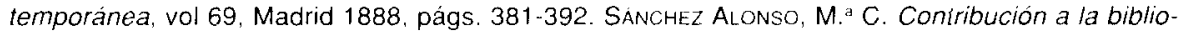
grafia de impresos españoles de temática madrileña (1450-1700). Tesis doctoral, Universidad Complutense, Madrid 1982. Amezua r Mayo, A. G. de, "Ei Bando de Policía de 1591 y el Pregón General de 1613 para la Villa de Madrid". RBAM, X, n." 38, Madrid 1933, págs. 141-179. ANDRÉs, G. de, "Ordenación urbanística de Madrid dada por Felipe II", AIEM. XII, Madrid 1976, págs. 15-31.

8 Memorial sobre las obras de Madriz, AGS, C y SR, leg. 247. Interesante escrito, sin techa ni firma, en el que se expone al rey una serie de medidas para embellecer la ciudad y dotarla de los servicios que deberia tener una capital de su rango. Este Memorial se tuvo que redactar entre 1564 y 1566 y su autor debió ser el Corregidor de la Villa don Antonio de Lugo, si no el propio Juar, Bautista de Toledo, quien, en caso de no redactar directamente el escrito, es desde luego el inspirador del mismo debido al tema que se trata y a las soluciones que da a los problemas que plantea la ciudad. además de que en numerosas ocasiones se hace referencia a él como arquitecto de la Villa, según afirma Camara Muñoz. A. Elementos manieristas en la arquitectura del primer barroco español: arquitectura y sociedad en el reinado de Felipe III, Madrid 1987. Ver también RiverA. J Juan Bautista de Toledo y Felipe I/ (La implantación del clasicismo en España), VaIladolid 1984.

9 Xerez, J., Deza, L. Razon de Corte, BN. Mss. 6.549 
La cuestión es tratar de comprender porqué Pérez de Herrera se siente en la obligación de plantearse reformas de carácter urbanístico en Madrid y la razón no puede ser otra que la visión de los cambios que se han producido en la ciudad desde 1577, cuando la visita primera vez, a 1592 cuando vuelve, al ser nombrado Médico de Casa y Corte. En este tiempo se ha producido un vertiginoso aumento de población, el caserío se extiende de forma prácticamente incontrolada y el aspecto que debía ofrecer era bastante negativo ${ }^{10}$. Además, pronto se cierne sobre la Villa el temor de perder su puesto como capital. En los últimos años de vida de Felipe II el rumor de una mudanza de la corte se hace cada vez más insistente y esta situación impele a Pérez de Herrera a actuar, pues para él es imprescindible mantener una capital fija y con el adecuado ornato que refleje el poder de la monarquia que la sustenta. La Corte debe servir de imagen al mundo y convertirse en arquetipo para el resto de las ciudades del reino.

Así a finales de 1597 y principios de 1598 escribe un discurso a Felipe Il sobre el urbanismo de Madrid y las mejoras que se podrían realizar en la ciudad a fin de nombrarla corte perpetua ${ }^{11}$, discurso que prácticamente repite y envía a Felipe III, el 13 de enero de $1600^{12}$, cuando el traslado de la Corte se presenta inminente, y una vez decidida oficialmente la mudanza, publica un nuevo alegato a favor de Madrid ${ }^{13}$. La principal diferencia que exisie entre el memorial enviado a Felipe II y el escrito a Felipe III estriba en que, en el primero, se hace una loa de Madrid haciendo referencia a las

(1) Sirva como ejemplo la descripción que hace de la Villa un acompañante del Nuncio Apostólico Camilo Borghese, tras su visita a Madrid en 1594: «La Villa dei Madrid... è assai grande, piena di popoli... Ha le strade larghe, le quale sariano belle. se non fusse il fango e la sporcità che hanno... Le case sono cattive et brutte el fatte quasi tutte di terra, e, fra le altre imperfectioni, non hanno camini ne cesse per lo che fanno tutti il loro bisogni ne i vasi, quali votano poi nella strada, cosa che rende un fetore intollerabile...". Relation du voyage en espagne de Camillo Borghese... 1594, en ANiEZUA A. de, "El Bando de Policia de 1591 y el pregón general de 1613 para la Villa de Madrid", RBAM, n. 38, Madrid 1933, pág. 141

Discurso a la catolica y real Magestad del Rey D. Felipe nu'estro Señor. en que se suplica. que considerando las muchas calidades y grandezas de la villa de Madrid, se sirua de ver si conuendria honrarla. y adornarla de muralla, y otras cosas que se proponen, con que mereciesse ser Corte perpetua, $y$ assistencia de su gran Monarquia. BN, R/ 28.762. Editado en 1598.

A la Católica y Real Magestad del Rey don Felipe III nuestro señor: suplicando á su Magestad. que atento las grandes partes y calidades desta villa de Madrid, ser sirua de no desampararla, sino antes perpetuar en ella la assistencia de su casa y gran Monarchia. BN, VE 56/44. Editado el 2 de febrero de 1600.

13 Cerca de la forma y traza cómo parece podrian remediarse algunos pecados, excesos y desordenes en los tratos, bastimentos y otras cosas de que esta villa de Madrid al presente tiene falta. y de qué suerte se podrian restaurar y reparar las necesidades de Castilla la Vieja, en caso de que Su Majestad fuese servido de no hacer mudanza con su corte a la ciudad de Valladolid. $B N, \vee 1136-32$. 
ciudades que podrian usurparle la capitalidad pero sin concretar en ninguna, mientras que el segundo especifica claramente las ventajas que Madrid posee sobre Valladolid. En el discurso que escribe en último lugar, expone por extenso la política edilicia que habria que llevar a efecto para mejorar la vida en Madrid. y que ya había apuntado en el memorial fechado el 13 de enero de 1600 , a la vez que propone una serie de arbitrios generales para desarrollar la economía de Castilla la Vieja. Estas tres obras manifiestan el ideal de ciudad que tiene Pérez de Herrera.

Dejando claro que es fundamental mantener una capital estable ${ }^{14}$, pasa a estudiar, la ciudad más adecuada para ello y no encuentra otra más a propósito que Madrid, primero porque ejerce de hecho como capital por propia elección de Felipe II, pero fundamentalmente por las posibilidades que ve en ella, "podria ser con el tiempo el lugar mas ilustre y populoso del mundo" " ${ }^{15}$. La concepción que tiene de la ciudad como un objeto sobre el que se puede intervenir para mejorarla en estructura y alzado, adecuándola a la función a la que está destinada para lograr que adopte una imagen específica es una idea que conecta a Pérez de Herrera con la teoría renacentista formulada por Alberti en De Re Aedificatoria, quien afirma que puesto que la ciudad ideal no existe hay que dotar de lo necesario a la existente ${ }^{16}$.

Una vez elegida Madrid como capital ${ }^{17}$, hace toda una loa a sus múltiples cualidades, valorando su limpio cielo, los aires saludables que la refrescan, el agua abundante que posee, su situación en un terreno elevado ${ }^{18}$, además

14 «Costvmbre ha sido y es muy antigua de todas las Monarquias y Reynos auer auido en ellos vna ciudad particular, y lugar fundado a proposito, con grandeza y otros requisitos de edificios, y ornatos conuinientes para habitacion y assiento de las Cortes, y moradas de los Reyes y señores dellos... como refiere Plinio". BN, $\mathrm{A} / 28.762$, Ibidem, f. $1 \mathrm{v}$.

lbidem, f. $2 v$.

16. "Agrademos pues imitar aquello de Platon que como fuesse preguntado, donde vuiesse de hallar aquella esciarecida ciudad que los auia fingido respondio: No tratamos esso, antes auemos andado inuestigando en que manera conuenga ordenar vna ciudad para que sea la mejor de todas. $Y$ tu ten que aquella se ha de preferir a las demas, que menos errare de la semejança de esta". AlBERTI, L.B. De Re aedificatoria. O los diez libros de arquitectura. Traducidos del latin por Francisco Lozano, alarife de la villa de Madrid a la vista del texto toscano de Cosme Bartoli, académico florentino y con los grabados de este (1565), Madrid 1582, pág. 110.

Sobre la elección de Madrid como capital del reino por parte de Felipe II. FERnANDEZ ÁlvaREZ, M. El Madrid de Felipe II. En torno a una teoria sobre la capitalidad. Discurso de ingreso en la Real Academia de la Historia, Madrid 1987, y Alvar Ezoverra, A. "El traslado de la capitalidad de Toledo a Madrid en 1561" en // Jornadas de estudios sobre la provincia de Madrid, Madrid 1980. págs. 126-142. Felipe II. la Corte y Madrid en 1561. Madrid 1985. y El nacimiento de una capital europea. Madrid entre 1561 y 1606 . Madrid 1989

Es significativo señalar que al enumerar cada uno de estos elementos sigue, incluso en el orden de exposición. los elementos que estudia Alberti a la hora de planificar la fundación de una ciudad ideal. 
de estar en el centro de la península, argumento propio de la mentalidad renacentista que usa al hombre como medida del mundo ${ }^{19}$ y considera trascendental el simbolismo de que la capital del reino esté en el centro del mismo ${ }^{20}$, buscando la perfección en la proporción y la geometria ${ }^{21}$. De las condiciones geofísicas de la villa pasa a reseñar los monumentos que la adornan: el palacio, los jardines y bosques, los Sitios Reales que rodean la villa, los edificios religiosos y de particulares que se construyen y reforman favoreciendo la existencia de nuevos aposentos, con lo que la ciudad gana en ornato, gracias a la Junta de Policia que fija la traza de las construcciones ${ }^{22}$. Todas estas cualidades junto con las mejoras que en la ciudad se están realizando ponen de manifiesto que la mudanza de la corte es un despropósito económico que tira por la borda todos los esfuerzos realizados para hacer de Madrid una ciudad capaz de asumir su función de Corte y por lo tanto imagen de la monarquía.

Una vez señaladas las ventajas que Madrid ofrece sobre el resto de las ciudades de España, pasa a proponer un auténtico plan urbanístico para engrandecer y dar más prestigio a la villa, "cinco cosas parece ser necessarias que V.M. se sirua mandar hazer para el ornato de la villa de Madrid... cercarla de muralla...dandole titulo de ciudad, hazerle Iglesia Catredal (sic). Obispado, y acrecentarle el rio que tiene... "23.

La muralla es inseparable de la idea de ciudad y, aunque a finales del siglo Xvi. su función defensiva es más simbólica que real, sigue siendo un importarite instrumento de control fiscal y sanitario. La propuesta que

\footnotetext{
Esta idea antropomórfica de la ciudad que tiene Pérez de Herrera se puede rastrear desde Alberti. Antonio Averlino (Filarete). y especialmente en Francesco di Giorgio Martini quien considera que el hombre está en el centro de la naturaleza porque es el ser principal de la creación. por lo que es el modelo a imitar, tanto para ordenar la ciudad como para ordenar un territorio más amplio. por lo que cla principale città si avesse ad adificare ... il loco suo conveniente è il centro del territorio", citado en PAVIA, R. Lidea di citta. Teorie urbanistiche della città tradizionale, Milán 1994, pág. 33 .

"que este sitio sea el mas conveniente para el lugar de donte salga el gouierno de todo el cuerpo. lo enseño la naturaleza en el mundo grande y pequeño. dando al Sol el lugar medio en los cielos... y en el cuerpo humano al coraçon este principado y assiento". Ibidem. $\mathrm{t}$. $8 \mathrm{r}$.

Camara Munoz. A. "Modelo urbano y obras en Madrid en el reinado de Felipe ll", en Madrid en el contexto de lo hispánico desde la época de los descubrimientos, Madrid 1994, pág. 33.

2 "que todas las casas viejas que se fabricaren de nuevo, no lo puedan hazer los dueños. sin dar parte a la dicha lunta. donde se les de el modo y traça con que han de edificar. haziendolas retirar dentro. o salir a fuera de las dichas calles, con muy buen modo de architectura. conforme a la traça que está acordada general sobre ello. de manera. que quedando en proporcion y niuel. hermosearan y adornaran la Corte de V.M. de suerte, que en espacio de treynta o quarenta años, a lo mas, vendran a ser todos los edificios della nueuos y luzidos y proporcionados". BN. R-28762.f. 6 r.

lbidem, tol. $11 \mathrm{r}$.
} 
Pérez de Herrera plantea es la de potenciar la función ornamental de la misma. Según su proyecto la nueva muralla se construiría por el arquitecto de obras de Madrid, Francisco de Mora, junto a otras personas que entendieran de fortificación ${ }^{24}$, levantándola de ladrillo y cal, excepto sus cimientos ${ }^{25}$, para que en caso de necesidad se pudiese transformar en una muralla defensiva ${ }^{26}$. Tampoco considera necesario elevar excesivamente sus muros ${ }^{27}$, tan sólo lo necesario para conseguir la sensación de seguridad en los vecinos: "que la muralla no fuesse muy alta, ... ancha algo mas que las ordinarias destos Reynos, y galana... por la parte de fuera ... de los ladrillos gruessos dichos galanamente puestos, reuocados de cal por las orillas, con sus almenas de lo mismo... haziendose torreones, caualleros, o traueses a cada mil y quinientos pies, o como mejor pareciere" "28. Es interesante señalar el apropiado lenguaje que utiliza Pérez de Herrera sobre términos de fortificación: torreones, cabalieros, traveses, acorde con su conocimiento directo de la vida militar, aunque al mencionar las almenas, elemento claramente regresivo, hace referencia a la importancia que para el doctor tiene la imagen de la muralla tradicional, y la almena es un elemento que recuerda a las fortalezas antiguas y dota de prestigio a la obra.

El carácter de representatividad de la muralla se hace patente al rodear el alcazar, "la muralla que estuuiese alrededor de la casa Real de V.M.

- Sobre la conveniencia de que en obras de fortificación de ciudades intervengan tanto ar. quitectos como personas expertas. es decir ingenieros. y sobre la importancia que va a tener la profesión de ingeniero a la hora de informar sobre las fortificaciones en el territorio de la monarquia hispánica. consultar A. CAMAKA MunOz. "La arquitectura militar y los ingenieros de la monarquía española: Aspecios de una protesion (1530-1650) . Revista Universidad Complutense. Ma. drid 1981, pags. 255-269. y Fortificación y ciudad en los reinos de Felipe 1I. Madrid 1998.

El uso del ladrillo como material constructivo en vez de la piedra nos remite al pasado mi. litar del doctor. ya que la experiencia enseñó que frente a la artilleria eran más resistentes los muros de materiales pequeños y flexibles que los grandes bloques pétreos. como muy bien explica el capitán Cristóbal de Rojas en su tratado sobre la construcción de fortalezas: "que la fabrica de ladrillo. siendo bueno y bien fabricado ... es muralla mas fuerte contra el artilleria. que no la piedra. porque es fabrica hecha de pieças muy pequeñas. y quando de vna vala de artilleria en la muralla de ladrillo. no atormenta ni rompe mas cantidad de aquello en que da la pelota. ROJAS. C de. Teorica y practica de fortificacion. conforme a las medidas y defensas destos tiempos. repartida entres partes. Madrid 1598, tol. $70 \mathrm{~V}$.

Esta posibilidad la explica Gonzalez de Medina Barba en su tratado al hablar de la transformacion de antiguas fortalezas en nuevas defensas. podriamos extrapolar esta situacion y fortalecer de igual modo. en caso necesario. una muralla de carácter ornamental y fiscal. GONzALEz DE. Meoina Bafba. D. Examen de fortificación. 1599. BN, R 31.000

La altura no muy elevada de los muros es una novedad que introducirán los ingenieros en sus construcciones. dado que iras la experiencia de ataques con artilleria pesada en diversos sitios a ciudades y fortines. se demostró que muros muy altos eran más débiles a la hora de sufrir el impacto de una bala y que "la artilleria del enemigo bate con mas pujança de abaxo para arriba: Gonzalez de Medina Barba. D. op. oit.

BN. R-28762. tol $16 \mathrm{~V}$ 
estara bien baxa. por la altura del sitio del palacio, pues por ninguna parte impedira la vista de la Casa del Campo, ni rio, sino antes sera de grande ornato del" ${ }^{25}$, la explicación no es otra que ser la capital un simbolo del poder real, por eso debe poder apreciarse la magnificencia del palacio en el que vive el monarca. Otro punto donde se concentra el carácter representativo de la muralla es en las puertas, donde se acumulan los elementos que hacen referencia al pasado glorioso de la ciudad y sus moradores ${ }^{30}$, en ellas se colocan los escudos de armas del monarca, o la familia a quien pertenece la villa y se ornan con fuertes almohadillados que expresan el poder que desean irradiar ${ }^{31}$. Cuando Pérez de Herrera fija unos nuevos límites para Madrid, cuida especialmente del diseño de las puertas de las calles de Atocha, Carrera de San Jerónimo, Alcalá, Hortaleza, puente de Segovia y de Toledo, que dan paso a las principales vías ceremoniales que recorren los cortejos en las festividades, proyectándolas con triple vano, como auténticos arcos triunfales clásicos ${ }^{32}$. En total sugiere realizar nueve grandes puertas y algunos postigos intermedios que, como la muralla, pierden toda función defensiva y se entienden como un límite de la vida urbana ${ }^{33}$. Las puertas como arcos triunfales demuestran el conocimiento que Pérez de Herrera tuvo de los tratados arquitectónicos renacentistas, ya Alberti indicaba: "Hanse de adornar las puertas no en otra manera que los arcos de los triumphos..." ${ }^{34}$ y Palladio también se refería al uso de arcadas y arcos triunfales para prestigiar más una determinada

BN. R-28762, fol $17 \mathrm{~V}$

3. Camafia Munoz. A. "Murallas para la guerra y la paz. Imágenes de la ciudad en la España del siglo xvi». Espacio. Tiempo y Forma. Madrid 1993. págs. 149-174.

Asi lo aconseja Serlio en su tratado. Libro IV, y se ve en la obra del capitán Cristóbal del Rojas quien. aunque reaimente no trata de como ha de ser la tipoiogia de las puertas de las fortalezas y ciudades. cuando tiene que ilustrar su libro elige, tanto para la portada del mismo, como para ilustración de una puerta de fortificación, unos vanos distintos entre si, según el lugar que ocupan en la obra, pero que en ambos casos estan coronados por sendos escudos.

"vna puerta principal de tres arcos de galana perspectiua para ornato de aquel camino tan frequentado. el de en medio dellos con puertas para en tiempo de necessidades de peste y contagios... cerrandose entonces las dos colaterales con tapias para guardar no entre gente". BN. R-28762, 1. 11v-12r.

Históricamente las entradas a la ciudad delimitan el mundo urbano puesto que sirven de frontera para marcar el pago de aranceles y controles sanitarios. Pero también marcan el desa. rrolio urbano de la propia ciudad. las puertas que comunicaban cor los caminos más frecuentados marcan ía zona de crecimiento de la misma e irán avanzando por el camino según la ciudad. al crecer, las rebase y se precisen nuevos limites. Un ejemplo de este tenomeno en Madrid es la puerta de Guadalajara. situada en el camino que unia la Villa con esa localidad. al crecer la ciudad hacia el Este el antiguo monumento queda enguilido por el caserio. pero en los nuevos limites se irán construyendo airas puertas, ya denominadas de Alcalá que se irán edificando en el camino para marcar los nuevos limites de la ciudad hasta la ultima construcción del siglo xvill. que todavia domina el antiguo camino. hoy calte de Alcalá.

A. Alberti. L.B. op. cif. pág. 248. 
calle, la entrada de una plaza, "Los arcos dan grandissimo adornamento a las plaças y se hacen al principio de las calles es a saber en el entrar a la plaça los cuales como se deben hacer y por que antiguamente se hacian y de donde se llamaban triunfales difusamente se dira en mi libro de los arcos...» ${ }^{35}$, por extensión podemos trasladar esta idea del arco triunfal en una calle o plaza, a la entrada de la ciudad. tal y como hace Pérez de Herrera ${ }^{36}$.

El cercar a Madrid de una muralla, aunque no muy potente sí vistosa, cumple, a juicio del doctor otra función, si la ciudad está contenida y no se permite construir a sus vecinos fuera de la cerca deberá obligatoriamente crecer en altura eliminando así, según pase el tiempo, las casas bajas que tanto afean la visión de las calles, y por supuesto también las realizadas "a la malicia, de poca bivienda y autoridad" 37, al acabar con estas casas se mejoraba la imagen de los edificios y el orden público, ya que las gentes que ocuparan las nuevas casas no serian de mal vivir; no tuvo en cuenta el doctor, que con evitar la visión de gentes de mísera condición no se acababa con su existencia.

Más interesante es su propuesta de favorecer la edificación de nuevas casas a través del incentivo de las exenciones en la regalía de aposento a condición de labrar según determinada traza, propuesta que realmente se practicaba en las principales vías de Madrid, en la calle de San Jerónimo y la de Atocha ${ }^{38}$. Pérez de Herrera se muestra, en este caso, excepcionalmente optimista al calcular los beneficios que se obtendrian ${ }^{39}$, y considera que podría sacarse dinero suficiente para ir acometiendo la obra de la muralla e incluso la del acrecentamiento del río, ayudándose, eso sí, del trabajo forzado de aquellos que delinquieren en la mendicidad cuando funcionara plenamente su sistema de Reformación de los Pobres en los Al-

Palladio. A. Libros $/ y$ /II. traducidos por F. Praves, Valladolid 1525, pág. 33.

Esta propuesta se relaciona con el exito de las últimas edificaciones de puertas realizadas en las murallas y fortalezas del reino (la puerta de la Bisagra de Toledo, la puerta de las Granadas en la Alhambra, el Portal Fosc de la fortaleza de Peñiscola. la Puerta del Mar en lbiza) y que el modelo de portada triunfal. siguiendo en el almohadillado de los sillares que las forman el estilo rústico marcado por Serlio, y la decoración de grandes escudos, se han convertido en arquetipo. BN. R-28762, fol. 13r.

30 Rueio PARoOs. C. "La calle de Atocha", AlEM, IX, Madrid 1973, págs, 81-116, Y "La Carrera de San Jerónimo", AlEM. VI, Madrid 1971, págs. 61-120

"dando cada vno dinero bastante de ciento y cincuenta hasta dozientos y trezientos ducados. y otros más y menos. contorme el grandor y sitio de las mesmas casas, obligando a los dueños dellas, pues no son las mas de los pobres que las biuen. sino de gente de caudal y descar:sada que las alquila, a que las compongan y tabren con la traça dada.... en tiempo limitado y señalado. o las vendan por su justo valor. pudiendo la villa tomarlas para este fecto por el tanto". BN, R-28762. fol. $13 \mathrm{v}$ 
bergues ${ }^{40}$, de esta manera se abarataban costes y se lograban dos objetivos de toda sociedad bien gobernada; la realización de obras públicas y el castigo de ociosos y delincuentes.

Una vez amurallado Madrid de forma monumental, será prioritario cambiar su título de "villa" por el de "ciudad" y hacer Obispado ${ }^{41}$. El título de ciudad comprende que es algo meramente nominal, pero contribuye a "crear imagen", para conseguir esta imagen no duda, incluso, en cambiar el nombre de Madrid por el de "Filipica, o Filipa, o Filipina, tomandolo de V.M. y del Principe nuestro Señor" o mejor, "Felipica, Felipa, o Felipina, $u$ otro nombre que en si incluya este, para que de esta suerte signifique ciudad de Fè, $y$ de Felipe Rey" "42, basa su pretensión en el uso de antiguos grandes monarcas, como Alejandro Magno y otros grandes príncipes fundadores de cludades que usaron su nombre para denominarlas ${ }^{43}$. También propone que esta propaganda distintiva de la monarquía hispánica se complete con que todos los reyes se llamasen o apellidasen Felipe, seguido del ordinal correspondiente, al uso de los romanos, con la particularidad de que en el caso de España, debido a la coincidencia de iniciarse con la sílaba $\mathrm{Fe}$, relativa al fervor católico que impera en el ambiente, se da lugar a que el nombre de los reyes y el de su corte son un emblema de poder y una profesión de fe, algo muy apreciado a la época, que tanto gustaba de los emblemas y los jeroglíícos ${ }^{44}$.

\footnotetext{
Segun su propuesta para acabar con la mendicidad fingida, grave lacra de la sociedad del momento. Se debería examinar a todos los pobres para que los verdaderos fuesen acogidos en $\mathrm{Al}$ bergues donde se podrian cobijar, además se les darian acreditaciones con las cuales podrian ejercer la mendicidad en determinados lugares. de esta manera se protegeria a los verdaderamente necesitados y se obligaría a los vagos y delincuentes a que trabajaran en oficios rentables o en las obras públicas que se realizaban en las ciudades. El albergue de Madrid se empezó a construir en septiembre de 1596. Todas sus propuestas en materia de pobreza las recoge, tras di versos memoriales y discursos en Amparo de pobres. Madrid 1598.

"honrar esta su Corte con darle titulo de ciudad, y hazerle Obispado. con su Iglesia Catre. dal (sic), que han de ayudar a la autoridad y grandeza deste lugar. las quales son correlatiuas vnas de otras. porque del hazerse la vna. se sigue la consequencia de las otras dos", BN, R 28762. fol. $18 \mathrm{r}$.

4. Ibidem, fol. $18 \mathrm{v}$.

4. Argumento ya usado en época del emperador para denominar una nueva ciudad, será el caso de Carlentini en Italia que une en su sombre el de Carlos $V$ y la antigua ciudad a la que trata de sustituir, también se toma el nombre del rey para fundar Felipeia en Brasil, en 1585, y ésta era la propuesta que en 1588 se le hace al monarca desde Italia, que en el estado de los Presidios, se fundara una nueva ciudad denominándola Filippaustria, para perpetuar la memoria del rey y la dimastia. Camara Munoz. A. "La ciudad de los ingenieros y la monarquia española: Tiburzio Spannocchi y Giulio Lasso", en CASAMENTo, A.. Guidoni. E. (dirs): L urbanistica del cinquecento in Si cilia. Roma 1999. pág. 21

¿4 Hace hincapié del gusto por el emblema en época de Felipe III. BATAll ION. M. Picaros y picaresca, Madrid 1982. Sobre el trecuente uso de emblemas en general. ZAFrA. R. y AZANZA, J.J (Eds) Emblemata Aurea. La emblemática en el arte y la literatura del siglo de oro, Madrid 2000.
} 
La materialización del Obispado en la ciudad es la catedral, un tema de suma importancia por su significación dentro del entramado urbano de la villa ${ }^{45}$. La construcción de una catedral en Madrid es asunto que se trata desde que la villa empieza a significarse como residencia frecuente de los reyes ${ }^{46}$, en el Memorial de las Obras de Madriz de $1564^{47}$ y en 1576 cuando el Ayuntamiento de Madrid pide al rey que levante una iglesia Catedral o Colegiata y se inician los estudios pertinentes ${ }^{48}$; sin embargo ninguna de estas propuestas llegará a término.

Al tratar de la catedral, Pérez de Herrera, tal y como hacen todos los tratadistas de arquitectura, indica el lugar en el que se debe ubicar el edificio proponiendo que se construya sobre la parroquia de Santa María ${ }^{49}$, esta localización (prácticamente la que actualmente tiene la catedral madrileña), enlaza el nuevo edificio con la historia de la ciudad, ya que Santa Maria es desde antiguo la iglesia principal de la villa y estaba muy relacionada con la vida palaciega, puesto que a ella acudirán todos los cortejos reales al hacer su entrada en la ciudad para orar antes de llegar a palacio. También, remite a la tratadistica renacentista el unir la catedral, edificio del poder religioso, con el palacio, que simboliza el poder político ${ }^{50}$. Para que no se pierda esta conexión catedral-palacio da como alternativa, si no se acepta el solar de la iglesia de Santa María, construirla

45 A tan importante tema Pérez de Herrera dedica más de un memorial al rey, el de 1598, y un discurso especifico: La forma que parece a propósito tenga la traça de la Yglesia Cathedral o Collegial desta Villa de Madrio. BN, Ms. 20065-28.

46. González Dávila indica que a principios del siglo xvi hubo intentos de construir una catedral $y$, dadas las trabas que se pusieron, se tuvo que abandonar el proyecto: “En el año 1518. Se trató de diuidir el Arçobispado de Toledo por ser lan grande, y que MADRID se erigiesse en Iglesia Cathedral. El Papa Leon $X$ despachó sus Bulas en 23 de lulio deste año, y cometio el caso al Cardenal Adriano Obispo de Tortosa, al Obispo Cosença su Nuncio, y al Obispo de Ciudarodrigo; hallaron muchas dificultades, y cessò la platica para no boluer à ella" Teatro de las Grandezas de la Villa de Madrid Madrid 1623, pág. 13. En iguales términos QuintanA, J. A la mvy antigva. noble y coronada Villa de Madrid, Madrid 1629, fol 81r., LeON PINElo, A. Anales de Madrid (desde el año 447 al de 1658), ed. 1971, pág. 70. Y el cronista del siglo Xviil Álvarez de BaenA, J. A. Compendio Historico de las Grandezas de la Coronada Villa de Madrid, corte de la monarquia de España. Madrid 1786, pág. 55.

4) "lo Primero y mas principal que conbiene hazerse en esta villa es una yglesia colegial o cathedral", AGS, C y SR, leg 247, f. 257.

48 Corral, J. del: Madrid 1561. La capitalidad, 1990, pág. 99.

4 "los sitios que parecen, siruiendose V.M. dello, serian mejores para esta efeto, y para autoridad desta Corte, y prouecho y comodidad del Real palacio de V.M. son el donde al presente està la Iglesia de Santa Maria, por ser matriz, tomando para ello las casas de don Pedro de Po rras. $y$ las que fuessen conuenientes, de modo que derrivandose la isla de las que estan frontero del palacio de V.M. se descubriesse desde alli la lglesia» BN, R-28762, f. $19 \mathrm{v}-20 \mathrm{r}$.

50 Asi lo expresa Francesco di Giorgio Martini: "se concederá el sitio a la iglesia-catedral con la plaza de entrente, donde estará el palacio señorial con el que tenga correspondencia...., Trattati. L. 5. 5-20. 1. citado en Muratore. G. La ciudad renacentista. 1980, pág. 124. 
en el lado izquierdo del alcázar, "en aquel alto donde estan las casas del Fator (sic)", o bien "adonde al presente esta la parroquia è lglesia de san Gil's, en este caso con la ventaja de que se podría construir un pasadizo entre el alcázar y la iglesia, tal y como se hacia con materiales efímeros con motivo de los bautizos de infantes ${ }^{51}$. De esta manera la catedral sería el lugar donde se oficiaran todos los actos reales como juramentos de príncipes, bodas, exequias... ${ }^{52}$.

Sobre la construcción de la catedral también envía, a principios del XVII, un memorial al Arzobispo de Toledo ${ }^{53}$, en él se comprueba cómo tiene mejor definida su localización ${ }^{54}$ y las intervenciones que se deberian hacer alrededor para crear una amplia zona privilegiada en la ciudad, marcada por la presencia del poder tanto político como espiritual, que se definiría por medio de un trazado ortogonal de las calles, la creación de una gran plaza y la utilización de una arquitectura moderna y también homogénea en todos los edificios que delimitarian este área preferente, el alcázar real, la armería, la catedral y el palacio de los Uceda ${ }^{55}$. Comparando este documento con el memorial, de 1598, comprobamos que se busca crear una zona acorde a los ideales renacentistas concretando, con edificios de Madrid, los ideales de Palladio ${ }^{56}$.

51 Así se hizo en diciembre de 1571, cuando se celebró el bautizo del principe Fernando, las fiestas y celebraciones que se hicieron se recogen en numerosas relaciones, la del Mss. 11.773 fols. 543 y 545 de la BN, oira en el Mss $3-1.049$ de la Academia de la Historia. Ia de Juan de Torres, de 1572, BN. R-4.995; recogidas en SIMON DIAZ, J. Relaciones de actos públicos celebrados en Madrid (1541-1650). Madrid 1982, además de los datos que aportan las obras de Gil González Dávila y Gerónimo de la Quintana.

5. Hasta ese momento los bautizos se hacian en San Gil y las exequias en las Descalzas o en San Jerónimo el Real, donde también se celebraban las ceremonias de los juramentos de principes desde la jura del futuro Felipe II.

5. Sobre haver iglesia collegial en Madrid. documento transcrito literalmente en SIERRA CORE. L.LA, A., op. cit., págs. 243-247, indicando que pertenece a la sección de Manuscritos de BN pero sin especificar la signatura completa. que es la ya referida, Mss. 20.065-28. También estudiado por Camara Muñoz, A. "Dos propuestas de catedral para Madrid a comienzos del siglo xvil. Reflexión sobre una arquitectura imaginada", en Cinco siglos de Arte en Madrid (XV-XX), 1991, págs. 32-39. quien fecha el documento entre 1613 y 1618 , cuando se construye el palacio del duque de Uceda.

54 «a donde se quemó aquella casa junto a Santa Maria ... que haga proporción con nivel y cordel con la armeria de su Magestad", ibidem, fol 149r-v.

55 "Será cosa insigne de ver en un sitio muy capaz el Real Palacio del Rey Nuestro Señor con tanta grandeza y hermosura de torres y arquitectura como se va acavando y añadiendo luego la armeria y Cavalleriza y casa de Pajes e Iglesia Mayor y la surituosa cassa del Excmo. Señor Duque de Uzeda con pasadizo también a la dicha Iglesia y al otro lado fabricas de cassas muy lucida perpestiva y todo de forma que adornando a esta Corte con gran grandeza y magestad se vean unos edificios a otros", ibidem.

"dan tambien mucho adornamiento allandose al principio de una calle en lugar hermoso y espacioso del cual se vea el aspecto de alguna hermosa fabrica y particularmente de algun templo mas ansi como esta bien que aya muchas plaças esparçidas por la ciudad ". PALLADIO. Op. cit. pág. 33 
Insiste en que la construcción debe ser grandiosa, adecuada a la función que tiene que desempeñar la edificación y armónica con el vecino alcázar ${ }^{57}$. En cuanto al diseño propuesto se encuadra dentro de los parámetros tradicionales de la catedral gótica española de tres naves. No debemos olvidar que la catedral de Valladolid trazada por Juan de Herrera, en la que se está trabajando desde el segundo cuarto del siglo XVI, se resolverá con una planta de tres naves que se abre en una fachada con tres puertas, como un gran arco triunfal, $y$, aunque la verdadera novedad de esta catedral está en el uso de las medidas y proporciones, así como en el definitivo tratamiento clásico que se da a su interior, no podemos dejar de señalar las semejanzas que tiene con la catedral de Madrid ideada por Pérez de Herrera, influencias que se explican por la estancia del doctor en Valladolid mientras en esa ciudad residió la Corte de Felipe III. La mezcla de lenguajes arquitectónicos góticos y renacentistas era normal en la época, por eso tampoco debe extrañarnos la propuesta de incluir en el templo abundantes vidrieras, cuando, según los preceptos renacentistas, la tendencia es a alcanzar más luz pero que ésta sea blanca por medio de vidrios transparentes ${ }^{58}$, señala incluso el modelo de la catedral de su ciudad natal, Salamanca ${ }^{59}$, esta alternativa del gótico al discurso clasicista, es algo totalmente válido en el momento ${ }^{60}$ y no supone en absoluto una caracteristica retardataria.

Una última y ambiciosa obra propone Pérez de Herrera para hacer de Madrid una gran capital, que el pequeño río que atraviesa la villa "se aumente y haga algo caudaloso añidiendole (sic) otros rios o parte dellos" ${ }^{61}$, todo el caudal del Guadarrama y parte del Jarama. Entiende que la tarea no es pequeña y que no tiene conocimiento directo ni del terreno ni de la técnica y por eso pide "que siruiendose V.M. me llegue a verlo con Francisco

5) «Toda la fabricación que sea de piedra la más fuerte y lucida que hay a la forma de la que se labra y pone en el Real Palacio de su Magestad que aunque el ladrillo es cosa fuerte no es tan autorizada obra y esta a de durar muchos siglos y lucir templo que se hace en una corte de tanta Magestad y el de obra más nueva y primor bien es que sea con perfección fabricado y de esculturas excelentes las portadas y de perspestivas y arquitectura admirable si bien el sagrario, Claus tro. Sacristia, Cabildo y las demás officinas pueden fabricarse de ladrillo por escusar gran costa", Mss 20065-28, fol. 151 $\mathrm{V}$

58 Nieto, V., Morales, A. Checa, F. Arquitectura del Renacimiento en España. 1488-1599, Madrid 1989, pág. 240

5. "será de mucha gracia y ornato que alrededor de todo el ambito del cuerpo de la lglesia en lo alto della poco más debajo de las bidrieras aya un corredor de piedra labrado con primor de re lieves al modo de uno que tienen la insigne Iglesia de Salamanca con otros dos corredores más anchos a los lados del coro a donde se pongan dos organos de tanta perfección como conviene a templo tan insigne", Mss 20065-28, fol. $151 \mathrm{~V}$.

60 Camara Muñoz, A. "Dos propuestas...", págs. 36-39.

(6) BN, R-28762, tol. $21 \mathrm{r}$ 
de Mora, $y$ algunos ingenieros, $y$ entonces se podra dezir lo que se sintiere con mas certidumbre» ${ }^{62}$, con esta propuesta trata de aplicar los conocimientos adquiridos en las presas y embalses realizados en los Sitios Reales, en obras de carácter público, algo innovador ya que los avances técnicos que lograron los ingenieros del rey, bombas de agua y otros ingenios hidráulicos, no revirtieron en la mejora de las ciudades ${ }^{63}$. Al incrementarse el caudal del río se consiguen ventajas para la ciudad, especialmente en el ámbito higiénico sanitario (nunca se plantea aumentar el caudal del río para el consumo directo de agua, puesto que Madrid se abastecía de buenas aguas a través de sus famosos "viajes") ya que habria más agua para arrastrar todas las inmundicias que genera una villa tan populosa. También apunta una rentabilidad material al potenciar su capacidad piscicola ${ }^{64}$, con lo que vuelve a tratar de rentabilizar, para uso común, los conocimientos que sobre presas y aclimatación de animales se habían adquirido en los Sitios Reales. Por último propone que se abran acequias de riego y se instalen molinos y batanes de papel en sus riberas para evitar su importación.

Finaliza su Memorial indicando que aunque parecen muy costosas todas sus propuestas se encaminan al bien común y que con el tiempo serán ganancia perpetua de los estados ${ }^{65}$, haciendo suya la opinión de Castillo de Bobadilla ${ }^{66}$. La inversión en arquitectura era beneficiosa para el ornato de la ciudad y símbolo permanente de la memoria de sus constructores.

Todas estas propuestas se completan con medidas edilicias que definitivamente llevarian a la mejora de la ciudad. Considera que cuatro son los factores sobre los que hay que actuar: abastecer la ciudad, cuidar su limpieza, aposentar a todos los cortesanos y vigilar la moralidad de la vida ciudadana.

\footnotetext{
BN, R-28762. fol. $21 \mathrm{~V}$.

63 GARCIA TAPIA, N. Ingenieria y arquitectura en el Renacimiento español, Valladolid 1990 pág. 305

64 "criarse en él [río] con el tiempo diferentes generos de peres, y baruos, y otras diferencias, echandose para este efeto alguna buena cantidad de los estanques de la casa de Campo; donde ay tantos. y vedando la pesca del por el tiempo conueniente para la cria y aumento della, cosa tan necessaria para el sustento de los dias prohibidos de carne", BN, R-28762, fol. $23 \mathrm{r}$.

65 "Por ser cosa cierta, que lo que se gasta por las Republicas, y los señores dellas en obras de las mismas, no es lo que les empobrece, pues los edificios se quedan en pie adornando las ciu. dades, y el dinero que se gasta y distribuye entre los vassallos en breue tiempo buelue a poder de los Reyes..., que to que pone en necessidad a los Reynos es lo que sale fuera dellos, porque no buelue jamas", BN, R-28762, fol. $24 r$.

Ef: "Una de las cosas que mas ennoblece los pueblos, son los sumptuosos y magníficos edjficios, cuya memoria, aun despues de sus ruynas, permanece en los futuros siglos, y haze à los fabricadores dellos dignos de eterna fama." CASTILlO DE BobadLl LA. Politica para corregidores y señores de vasallos en tiempo de paz y de guerra. 1957, L III, c. V, 1, pág. 71.
} 
Aunque en el primer memorial que envía a Felipe III indica "que aunque ha casi quarenta años (desta vez) que assiste la Corte en ella [Madrid], nunca ha auido falta dellos, ni carestia notable» ${ }^{67}$, posteriormente, en el segundo ${ }^{68}$ propugna construir mercados y alhóndigas por tipos de mantenimientos, una Ionja para los negocios y más tahonas que surtan de pan a toda la ciudad, además de doce molinos de viento en los lugares más aventados de Madrid.

Con respecto a la limpieza en la ciudad, entiende como prioritario cuidar la bondad del agua ${ }^{69}$ y la purificación del aire, tal y como se exponía en todos los tratados de arquitectura civil o militar, desde Vitruvio. Para realizar la limpieza de las calles propone que cuarenta carros recojan las basuras de las vías públicas, cuyo coste sería sufragado por repartimientos entre vecinos, a través de un regidor que sería sobrestante mayor de la limpieza de las calles y vigilaría el repartimiento que se debe hacer para los carros y empedrar las calles regularmente. Los vecinos además, tendrían la obligación de barrer diariamente sus calles, amontonando la basura en medio de la vía para que fuera recogida por los chirriones y regar las calles en verano para refrescar el ambiente y evitar la formación de polvo ${ }^{70}$. Este sistema de limpieza de calles, coincide con la propuesta de Castillo de Bobadilla ${ }^{71}$, ejemplo de cómo las ideas de los reformadores contemporáneos son recogidas y utilizadas por el doctor.

6. BN, VE 56/44, fol. 6V.

68 BN. V-1136-32.

69 Para procurar que el agua no reciba suciedades que puedan infectarla, propone que se protejan las vías de agua y los manantiales no permitiendo que existan muladares cercanos a ellas y que se prohiba terminantemente verter basuras por encima de los lugares por donde discurre el agua de consumo, ya que, con las lluvias, estas inmundicias se unen a los cursos de agua potable. Sobre la importancia del agua como medida higiénica en las ciudades es interesantísimo el estudio de Blasco Esouivias, B. ¡Agua va! La higiene urbana en Madrid (1516-1716). Madrid 1998.

"un sobrestante mayor de la limpieza de las calles teniendo libro y razón del repartimiento que a cada vecino, de los que no fueren muy pobres, les cupiere, asi de la costa para los carros añadidos, como del empedrado de las dichas calles... [Los carros]podrían regar en las tardes del verano, con los cubos que suelen, los cuarteles de su repartimiento, y principalmente en las calles principales dellos, escusándose con ello el polvo tan excesivo y daños para la salud que en este lugar los más dias de verano se levanta por el mucho número de gente, coches y carros dél."en A la Catolica Real Magestad del Rey Don Felipe III, nuestro Señor: cerca de la forma y traça. como parece podrian remediarse algunos peccados, excesos y desordenes, en los tratos, vastimentos y otras cosas, de que esta villa de Madrid tiene falta... El D. Chistoval Pérez Herrera... 1600, citado en Amezú, A. G. de, op. cit., págs. 144-145.

"Para execucion de la limpieza suele aver en los grandes pueblos dada orden que aya executores, y bestias, ò carretones pagados por sisa, ò por repartimiento de los vezinos, voluritario, ò forçoso, con licencia del Concejo. Muchos pueblos he visto limpios de lodos y de otras inmundicias. $Y$ es gran parte para ello la curiosidad y policia de los vezinos que acostumbran cada dia hazer barrer, y en Verano regar sus puertas y pertenencias: lo qual devrian los Corregidores mandar que se hiziesse, y hazerlo pregonar de quando en quando, y es necessario en todos los 
Estas medidas sanitarias se completan con otras de control social a través del aposento cómodo de todos los cortesanos y la supervisión de la población por los "sindicos de la vecindad" para vigilar el empadronamiento de cada vecino y conocer en todo momento el número de habitantes de Madrid, su situación, oficios, etc. Además se trata de sanear moralmente la corte eliminando personas escandalosas y vagas con la reducción de los pobres auténticos en Albergues específicos y creando una normativa que obligue a que la población con capacidad de trabajo no permanezca ociosa.

Las propuestas y arbitrios del doctor Pérez de Herrera no pasaron de ser teorías, pero nos demuestran el interés que suscitaba el ornato y decoro de la ciudad, así como la necesidad que se veía de mejorar su imagen para adecuarla a su función de capital, por medio de una normativa que garantizara la higiene en la misma. Todas sus propuestas tratan de convertir la sociedad ociosa y cargada de vicios, en la que se halla inmerso, en un ejemplo de orden y laboriosidad que llevará a la consecución de la perfección moral y la riqueza general de todos sus miembros. Este fin último también se materializa a través de edificaciones, es decir, las propuestas del doctor regenerarían no sólo espiritual y socialmente la vida de la capital del reino, sino también físicamente, haciendo de la Villa de Madrid una ciudad digna de ostentar eternamente el título de capital del reino por su monumentalidad.

En este sentido hay que entender su proyecto del recogimiento de niños indigentes, con el fin de ofrecerles un futuro laboral útil a la sociedad, y de los pobres en albergues, así como la asistencia de los antiguos soldados y la asistencia sanitaria en general, además de la reducción y castigo de delincuentes y vagabundos ${ }^{72}$, todas estas propuestas precisan de edificaciones adecuadas, ya sea sanar, cobijar, instruir o penalizar comportamientos, que serán aprovechados por Pérez de Herrera para crear una zona monumental en Madrid, ubicándola en uno de los caminos más frecuentados por los cortejos festivos en las festividades religiosas, celebraciones laudatorias, etc., el último tramo de la calle de Atocha que a fi-

pueblos, en especial... en Granada, Toledo, Valiadolid. y Madrid. donde los lodos en invierno son tantos, y el polvo en Verano tan insufrible, que ensuzian y manchan los vestidos, y ofenden los sentidos...”. CAStillo de Bobadilla, op. cit., 1597, pág. 86.

Las medidas contra los vagabundos se completan con las encaminadas a castigar a las mujeres de mala vida, asi como se refuerzan a través de la instrucción de los huérfanos y la ayuda a los antiguos soldados, de tal manera que todos los elementos que podrian ser subversivos en la sociedad estén neutralizados. PEREz dE HERRE.RA. C. Amparo... Mas información acerca de las medidas proyectadas por Pérez de Herrera en GonzÁlEz dE LA FUENTE. D. op. cit. 
nales del XVI se estaba configurando. Allí se inicia, en 1596, la construcción del Albergue de pobres ${ }^{73}$ siguiendo la traza dispuesta en el proyecto inicial del doctor ${ }^{74}$. La obra, por consejo de Luis Gaitán de Ayala ${ }^{75}$ se le encargó a Diego Sillero ${ }^{76}$, quien la tomó a su cargo y costa, previéndose su terminación en dos años. El grandioso edificio debía ser modelo de otros albergues en ciudades principales que "a lo menos imiten en 10 más que pudieren esta trazas ${ }^{77}$. Este es el papel emblemático propio de una construcción de la capital del reino, ser el modelo en el que se miren todas las ciudades.

En esta construcción se proyecta incluir además del albergue de pobres, la reclusión de mujeres delincuentes, y el Hospital General, además de alguna otra obra pía, como hospital de peregrinos o similar, dada la gran capacidad que tenía. Pero más importante es que junto a este edificio en construcción se halla el Seminario de Santa Isabel, institución encargada de recoger niños pobres. En ella propone Pérez de Herrera que se materialice su propuesta de redimir a la infancia a través de la instrucción, al ofrecer a los niños allí recogidos la posibilidad de aprender un oficio útil a la sociedad con el que ganarse la vida y salir de la mendicidad. El proyecto era crear una amplia plaza en la delantera del convento de Santa Isabel, que enlazara las calles de Atocha y de Santa Isabel y delimitara un amplio espacio central rodeado de edificios dedicados a vivienda y talleres de artesanos. La propuesta prevé dar la viviendas de las tiendas a "oficiales naturales y estrangeros que se hallarán con mucha facilidad, dándeseles de balde" ${ }^{78}$ a condición de que enseñen su oficio a estos niños pero sin mantenerlos, ya que a comer y dormir acudirían a dicho seminario, de tal suerte que en poco tiempo se fabricarían aquí «muchas merca-

«Para el albergue que V.M. ha sido servido mandar se haga y fabrique en esta villa de Madrid. para el amparo de los legitimos pobres mendigantes desta Corte, he buscado muchos sitios con particular cuidado, y. entre muchos que he visto, no he hallado otro más a proposito que el en que está ya comenzada gran parte de la fábrica: porque. fuera de que costó muy poco el suelo y sitio, respeto de otros en los cuales se habian de derribar algunas casas. este. por ser solares y campo raso, es muy bueno y barato...". PEREZ de HeRRERA. C.. op. cit.. págs. 225-226.

lbidem. pág. 232.

Personaje fundamental para el desarrollo urbanístico de Madrid. ciudad de la que fue Co. rregidor entre 1581-1590 y presidente de la Junta de Policia de la Villa, organismo que trató de ordenar el crecimiento de la ciudad asi como la organización de la vida publica a través del control de la construcción. la distribución de zonas de venta y oficios. limpieza, orden público.... por lo que conocia en profundidad el funcionamiento de obras publicas de gran envergadura como el caso que nos ocupa. de aqui que se le pida consejo en este asunto.

Alarife de la Villa de Madrid del que asegura el propio Pérez de Herrera "ha hecho hacer todas las obras grandes desta villa", ibidem, pág. 235.

Ibidem, pág. 232.

lbidem. pág. 239 
derías curiosas que se traen de fuera del Reyno", logrando la diversificación de la industria interna con el consiguiente ahorro al no tener que importar productos extranjeros.

Además de la importancia social y económica de la propuesta es importante señalar que esta intervención tendría doble función, poner en valor un edificio, el Seminario de Santa Isabel y edificar una plaza siguiendo el modelo de las plazas mayores, como una construcción unitaria y moderna en una de las vías principales de la ciudad ${ }^{79}$. La edificación resultante permitiría mantener abierta la calle paralela a la de Atocha y a la vez crear un organismo uniforme a través de arcadas que también se construirian en la calle de Atocha, sirviendo de nexo entre las dos vías ${ }^{80}$. Como siempre el poder de la imagen y el hacer de Madrid un arquetipo para todo el reino están presentes, además con el uso de las arcadas el doctor está citando nuevamente uno de los preceptos del renacimiento expuestos por Palladio.

De haberse llevado a la práctica esta propuesta el final de la calle de Atocha, todavia un solar informe, se habría convertido en una zona monumental caracterizada por el grandioso edificio del albergue y la plaza a través de la cual se vislumbraría la fachada del Seminario de Santa Isabel junto al que también está propuesta la construcción de la Casa de la Milicia ${ }^{81}$, logrando asi una zona que manifestase la magnificencia, no tanto real como de toda la sociedad implicada en llevar a cabo la asistencia a necesitados, castigo de los descarriados y gratitud y premio a los servicios prestados que se materializaría en la Casa de Milicia. Este proyecto indica la nueva concepción que tiene el doctor Pérez de Herrera de la arquiteciura que, como creadora de imágenes visuales que ayudan a renovar la estructura de una ciudad, pone de manifiesto las intenciones de renovación de la sociedad, entendiendo que el carácter representativo y la utilidad de determinados monumentos y edificaciones, puestos al servicio

Para ello era necesario que "se derriben algunas casas de poco valor, que están en la delantera del dicho seminario, y se haga y allane alli una gran plaza, fabricandose a los lados ochenta tiendas, cuarenta de cada parte. siendo este edificio de suerte fabricado que no estorbe en paso y camino que va por delante la casa de santa Isabel. salvándose con unos arcos desde la dicha casa hasta el principio de la plaza”. ibidem.

*i: "pues teriendo tres o cuatro puertas principales a la calle de Atocha. con sus arcos y ca" denas. que por ellas se vea y descubra la tabrica del dicho Seninario. lucirán y parecerán muy bien las tiendas y oficiales, y todo el Reyno acudirá a comprar a ellas", ibidem. pang. 241.

«Pudiendose fabricar esta casa del amparo de la milicia junto al seminario de Santa Isabel... pues alli hay sitio a propósito para ello. para que los soldados viejos, marineros. pilotos y artilleros. y otros jubilados... instruyan y enseñen a los niños de havilidad. e inclinaciones a propó sito. del seminario...". Pehiez de Herrera. op. cit. pág. 284. 
del bien común de la república, pueden llevar a dinamizar las rígidas estructuras de la época y favorecer la inserción en la sociedad de sus miembros más desfavorecidos, a través de su control y capacitación para el trabajo.

En todas las propuestas subyacen los preceptos teóricos de los tratados arquitectónicos, de arquitectura civil o militar, escritos y manejados en el momento. Esta adecuación de los proyectos a la teoría es, en nuestra opinión, lo más importante de las propuestas de Pérez de Herrera, los gustos estéticos se van plegando a los avances técnicos y científicos que se logran. Se modifica la concepción de la ciudad rodeada de fuertes y altas murallas, por la cercada por una más liviana, cuya monumentalidad se centra más en las portadas que en el grosor y altura de los muros. Se buscan calles más amplias y rectas, en las que prima una buena aireación y la circulación cómoda de carruajes y, que en caso de necesidad, permitan el buen movimiento de tropas. Se tratan de abrir, en el antiguo entramado urbano, plazas con diversas funciones, además de la plaza mayor de carácter representativo y festivo, plazas de venta de determinadas mercancias, como la plaza comercial de productos de lujo proyectada frente al seminario de Santa Isabel, o la más importante y monumental plaza del palacio real, engrandecida por la presencia de una majestuosa catedral que daría más importancia a Madrid, la nueva Felipica, ya ciudad y no villa, y crearia en su entorno un espacio simbólico importante en conexión con el alcázar vecino y sus dependencias anejas, como las caballerizas reales, y los palacios de la alta aristocracia, en este caso el del duque de Uceda en aquellos momentos en construcción.

Las propuestas no se materializaron en el momento de elaborarlas pero con el tiempo se fueron realizando en su mayoría, demostrando su validez: se construyó la «cerca» de 1625 que sigue el perímetro propuesto por Pérez de Herrera ${ }^{82}$, se terminó el Albergue de pobres y se instaló en él el Hospital General, se mejoró la política edilicia con un mayor control de los abastos y la limpieza de la ciudad, se realinearon antiguas calles enderezando su trazado ${ }^{83}$.

8: Sobre las distintas murallas de Madrid, Camara Muñoz, A. y Gutierrez Marcos, J. (Coords.) Castillos. fortificaciones y recintos amurallados de la Comunidad de Madrid, Madrid 1993 y Pinto Crespo, V. y Madrazo Madrazo, S. (dirs.), Madrid. Allas histórico de la ciudad, siglos $I x-x i x$. Madrid 1995.

83. Un ejemplo fue la realineación de la calle de Platerias. VizCAinO, M. A. "La calle de la Platería en el Madrid del siglo XVII». AIEM. Madrid 1992, págs. 337-351. 
Estos proyectos presentados desde distintos ámbitos, tanto desde el mundo intelectual, como es el caso que nos ocupa, como de técnicos y poderes públicos, irán creando un clima favorable a la intervención sobre la ciudad que fraguará, como ya se ha apuntado, en la materialización de las reformas ideadas en el siglo XVI a lo largo del XVII cuando la economía permita realizar las inversiones necesarias para llevar a buen término las construcciones. Esta materialización de las obras tan alejada de su proyección nos indica tanto la falta de disponibilidad económica como, en ocasiones, los conflictos de competencia de los diversos organismos que debían intervenir en las obras, ya que el Concejo se resistirá a sufragar las reformas propuestas por parte de la Corona y la Corona tratará de no hacerse cargo de las reformas que ve necesarias en la ciudad. Pero la validez de las propuestas se demuestra precisamente en que, a pesar de haber transcurrido varias décadas desde que se escriben hasta que se realizan, mantuvieron la idea original. Incluso podemos entender que la construcción de la catedral de Madrid, en el lugar que hoy ocupa, frente al palacio del siglo XVIII, cerrando la plaza de la Armería, no es sino un remedo de la propuesta de Pérez de Herrera, por supuesto porque se busca la tradicional unión simbólica entre Iglesia y poder político, de ahí que palacio real y catedral sean edificios que traten de ponerse en relación para crear una zona monumental, una especie de témenos del poder. 
